\title{
Evaluation of the ocular blood flow and choroidal thickness in patients with chronic renal failure
}

\author{
Kronik böbrek yetmezliği olan hastalarda oküler kan akımı ve koroid \\ kalınlığının değerlendirilmesi
}

Enes DUMAN ${ }^{1}$, Öznur KAL ${ }^{2}$, Ali KAL ${ }^{3}$

ABSTRACT

In our study we want to evaluate the ocular blood flow and choroidal thickness of patients with chronic renal failure (CRF) who underwent regular dialysis and healthy individuals. Twenty-one patients (42 eyes) with diagnosis of CRF who regularly hemodialized and 21 healthy volunteers (42 eyes) as a control group were included in the study. Ocular blood flow was assessed with Doppler US and choroidal thickness was measured with optical coherence tomography (OCT). Ophthalmic artery (OA) mean maximum systolic velocity (Vmax) values were $56.23 \pm 19.22 \mathrm{~cm} / \mathrm{sec}$ in the left, and $61.80 \pm 18.24 \mathrm{~cm} / \mathrm{sec}$ in the right eyes, in patients with CRF, and, $40.04 \pm 7.90 \mathrm{~cm} / \mathrm{sec}$ in left, and $40.61 \pm 8.55 \mathrm{~cm} / \mathrm{sec}$ in the right eyes in the control group, respectively. The resistivity indices (RIs) were $0.77 \pm 0.05$ in right, and $0.77 \pm 0.03$ in the left eyes in $O A$, and in R/s were $0.65 \pm 0.03$ in right, and $0.66 \pm 0.02$. in the left eyes in the control group, respectively. Mean choroidal thickness was $165.36 \pm 51.29 \mu \mathrm{m}$ in CRF, and 291.79 $\pm 51.65 \mu \mathrm{m}$ in the control groups. In patients with CRF who regularly hemodialized; especially in $O A$, flow rate and $R I$ values were calculated higher than those of the control group, and there was a significant choroidal thinning compared to healthy individuals.

Keywords: Chronic renal failure, ocular blood flow, choroidal thickness, optical coherence tomography
Öz

Çalışmamızda düzenli diyalize giren kronik böbrek yetmezliği (KBY) olan hastalar ile sağlıklı bireylerin oküler kan akımının ve koroid kalınlığının değerlendirilmesi amaçlanmıştır. Çalışmaya $K B Y$ tanısı olan ve düzenli olarak hemodiyalize giren 21 hasta $(42$ göz) ve 21 sağlıklı gönüllü birey (42 göz) kontrol grubu olarak dahil edildi. Oküler kan akımı doppler ultrasonografi (US) ile değerlendirildi. Koroid kalınlıkları ise optik koherens tomografi (OKT) ile ölçüldü. Oftalmik arter (OA) ortalama maksimum sistolik hız (Vmax) değerleri KBY olan hasta grubunda sol gözde 56,23 $\pm 19,22$ $\mathrm{cm} / \mathrm{sn}$; sağ gözde $61,80 \pm 18,24 \mathrm{~cm} / \mathrm{sn}$; kontrol grubunda sol gözde $40,04 \pm 7,90 \mathrm{~cm} / \mathrm{sn}$ sağ gözde $40,61 \pm 8,55 \mathrm{~cm} / \mathrm{sn}$ olarak ölçülmüştür. OA'lerdeki rezistivite indeks (RI) değerleri sağ gözde

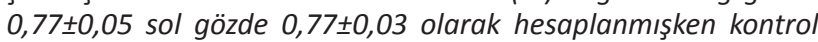

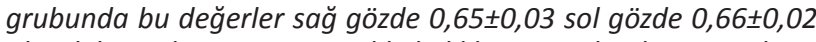
olarak hesaplanmıştır. Koroid kalınlıkları KBY olan hasta grubun-

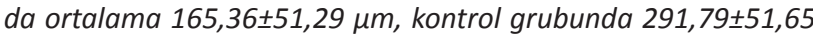
$\mu$ m olarak ölçülmüștür. KBY olan ve düzenli diyalize giren hastalarda özellikle OA'de belirgin olmak üzere akım hızı ve RI değerleri yüksek olarak hesaplanmış ve bununla birlikte koroid kalınlıklarında sağlıklı bireylere göre belirgin incelme görülmüştür.

Anahtar kelimeler: Kronik böbrek yetmezliği, oküler kan akımı, koroid kalınlığı, optik koherens tomografi

\section{Giriş}

KBY olan hastalarda ortaya çıkan metabolik bozukluklar sonucunda birtakım moleküllerin birikimi çeşitli organlarda toksik etki ile sonuçlanır. KBY sonucunda direkt veya indirekt olarak etkilenen bu organlardan birisi de gözdür. Bu güne dek yapılan çalışmalarda, KBY' de çeşitli göz bulguları saptanmış ve tanımlanmıştır. Bunlardan bazıları, gözyaşı salgısında azalma, konjonktiva ve korneada kalsifikasyon, göz içi basıncı değişiklikleri, retinal patolojiler (makülada pigmentasyon, koryoretinal atrofi, vasküler retinopati) ve optik sinir patolojileridir (optik nöropati, papil ödemi). Medikal destek tedavisindeki ilerlemeler, diyaliz tekniklerindeki gelişmeler ve böbrek nakli cerrahisindeki başarılar, KBY hastalarının yaşam süresini uzatmakta ve hastalığa bağlı gelişen komplikasyonları azaltmaktadır. Örneğin önceleri sıkça karşılaşılan ek-

Received: 07.09.2017

Accepted: 20.11.2017

${ }^{1}$ Department of Radiology, Baskent University, Konya, Turkey

${ }^{2}$ Department of Internal Medicine, Baskent University, Konya, Turkey

${ }^{3}$ Department of Ophthalmology, Baskent University, Konya, Turkey

Yazışma adresi: Enes Duman, Department of Radiology, Baskent University, Saray Cad. Hocacihan Mah. 42080 - Selçuklu - Konya - Turkey

e-mail: drenesduman@hotmail.com 
sudatif retina dekolmanı artık oldukça azalmıştır. Bununla birlikte, KBY'nin seyri sırasında gözün direkt ve indirekt etkilenimi devam etmektedir ${ }^{1}$.

Retina hastalıkları ve glokomda tanısal anlamda OKT önemli bir yer tutmaktadır. OKT ile normal retina muayenesi ile kolay fark edilemeyen patolojiler, kolaylıkla gösterilebilmektedir. Kantitatif sonuçlar veren OKT uygulaması da kolay olan bir görüntüleme aracıdır ${ }^{2-5}$.

Orbital vasküler kan akışındaki anormallikler renkli doppler ultrasonografi ile ayrıntılı olarak görselleştirilebilirler. Kapiller ve arteriolar düzeyindeki değişiklikler retinada anatomik değişiklikler meydana gelmeden önce renkli doppler ultrasonografi ile saptanabildiği bildirilmiş̧ir. Renkli doppler tekniğinin kolay uygulanabilmesi, tekrarlanabilir olması, invaziv olmaması gibi avantajları vardır ${ }^{6,7}$.

Bizim bu çalışmadaki amacımız, normal sağlıklı kişilerle karşılaştırıldığında KBY hastalarında oküler kan akımının ve koroid kalınlığının etkilenip etkilenmediğini değerlendirmektir.

\section{GEREÇ ve YÖNTEM}

Çalışmamız prospektif şekilde Kasım 2016 ve Mayıs 2017 tarihleri arasında yapılmıştır. Çalışmamız üniversitemiz Araştırma Kurulu ve Etik Kurulu tarafından onaylanmıştır. Çalışmaya KBY tanısı olan ve düzenli olarak hemodiyalize giren 21 hasta (42 göz) ve bunlarla birlikte hipertansiyon, diyabet gibi sistemik rahatsızlığı olmayan, steroid kullanımı olmayan, göz ile ilgili geçirilmiş hastalığı ya da ameliyatı olmayan 21 sağ lıklı gönüllü birey (42 göz) kontrol grubu olarak dahil edildi. KBY nedeni obstruktif üropati, taş, primer glomerulonefrit, sekonder pyelonefrit olan hastalar çalışmaya dahil edildi. Glokomu olan, sistemik hastalığı olanlar (diyabet ve hipertansiyon), steroid kullanım öyküsü olan, retina dekolmanı, makula patolojileri, koroid anormallikleri olan, yüksek derecede miyop ya da hipermetropu (sikloplejik sferik ekivalan olarak +6 ve -6 diyoptriden yüksek) olanlar, aksiyel uzunlukları 22 ve $24 \mathrm{~mm}$ arasında olmayanlar, geçirilmiş oküler cerrahisi bulunan kişiler çalışma dışı bıra- kıldı. Çalışma protokolu Helsinki bildirgelerine uygun olarak tüm hastalardan onam formu alınarak yapıldı. Tüm gözlerde renkli doppler incelemeleri EUP-L535 (Hitachi, Tokyo, Japan) ultrason cihazı ile yapıldı. Ölçümler hastalar supin pozisyonda, göz kapakları kapalı iken, prob üzerine metil selülöz jel konulduktan sonra prob göz kapakları üzerine yerleştirilerek yapıldı. Bütün ölçümler 7,5-MHz (Hitachi, EZU-MT2451, Tokyo, Japan) yüzeyel prop kullanılarak yapıldı. Her bir gözde oftalmik arter (OA) ve santral retinal arterlerin (SRA) doppler incelemeleri ayrı ayrı yapıldı; maksimum sistolik hız (Vmax), diyastol sonu hız (Vmin), rezistivite indeks (RI) değeri (Vmax- Vmin)/ Vmax formülü ile hesaplanarak kaydedildi. Doppler inceleme sırasında ölçümler, doppler ölçüm imlecine akım yönüne paralel olacak şekilde uygun açılar verilerek yapılmıştır (Figür 1).

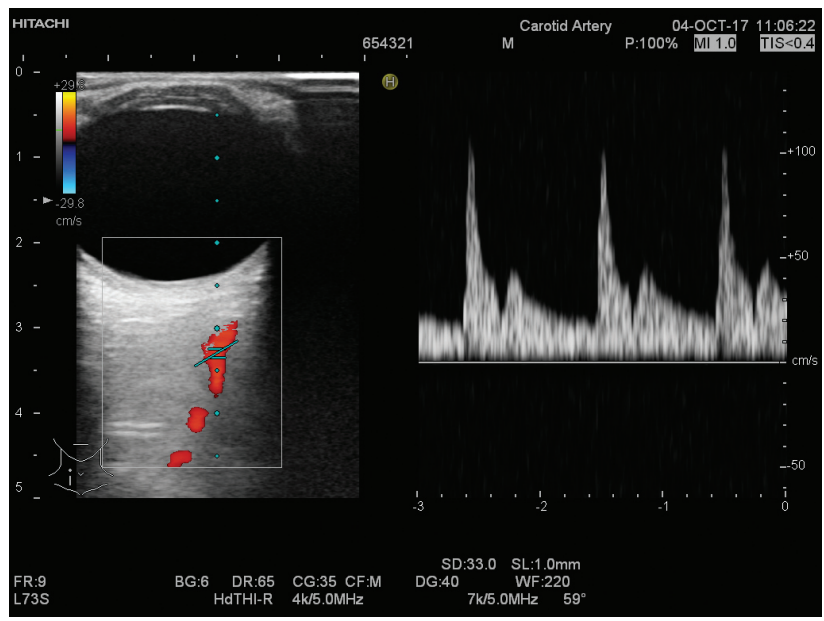

Figür 1. Oftalmik arter doppler incelemesi.

Koroid kalınlıkölçümleri ( $\lambda=840 \mathrm{~nm} ; 26,000$ A-tarama/ saniye; $5 \mu \mathrm{m}$ aksiyel çözünürlük özelliklerine sahip) spectral domain (SD) OKT (Optovue Inc, Fremont, CA) cihazı ile yapıldı. Koroid kalınlığı, retina pigment epitelyum tabakasının hiperreflektif dış sınırı (cihaz tarafından belirlenen) ile sklera-koroid arayüzü arası manuel olarak çizilen dikey çizgilerle ölçüldü. SDOKT ile subfoveal, foveaya 500 ve 1000 mikrometre mesafede nazal ve temporal koroid kalınlıkları iki kişi tarafından ölçülerek ortalaması alındı. Görüntüler iki kişi tarafından alınan ortak konsensusa uygun olarak değerlendirildi (Figür 2). 


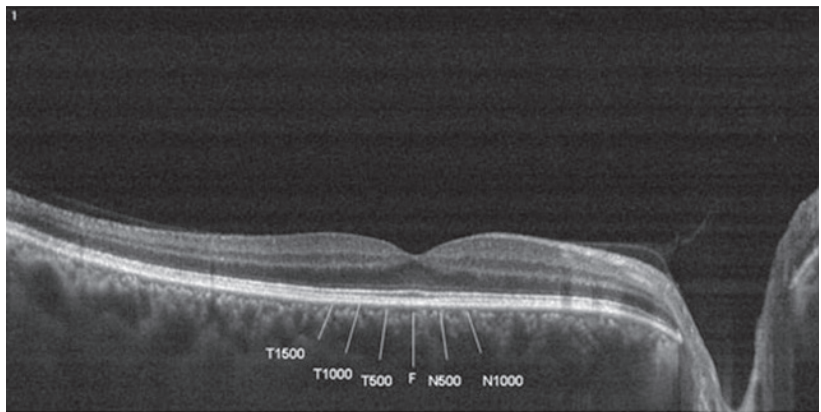

Figür 2. Bir hastanın OKT görüntüsü ve koroid kalınlığı ölçümü.

\section{İstatiksel analiz}

İstatistiksel analiz IBM-SPSS ("Statistical Software Package for the Social Sciences") 21 istatistik paket programı (Chicago, IL, USA) kullanılarak yapıldı. Sağlıklı ve $K B Y^{\prime} l i$ bireylerin yaş, diyalize girme süreleri, koroid kalınlıkları ve renkli doppler akım ölçüm verileri ortalama \pm standart sapma (SS) olarak belirtildi. Numerik değerlerde normal dağılım bakıldı. Sağ göz SRA Vmax değerleri hariç diğer nümerik değerlerde normal dağılım vardı, sağ göz SRA Vmax değerleri Mann-Whitney $U$ testi ile diğer karşılaştırmalar student $T$ testi ile yapıldı. Hastaların cinsiyet analizi ise ki-kare testi ile yapıldı. İstatistiksel olarak $p<0,05$ anlamlı kabul edildi.

\section{BULGULAR}

KBY olan 21 hasta (toplam 42 göz), 21 tane sağlıklı bireyin (toplam 42 göz) renkli doppler incelemeleri ve OKT sonuçları değerlendirildi. KBY olan hasta grubunun yaş ortalaması $63,57 \pm 13,79$ yıl kontrol grubunun yaş ortalaması $62,28 \pm 9,24$ yıl olarak bulundu. íki grup arasında yaş ortalaması benzerdi $(p=0,725)$. Her iki grupta cinsiyet dağılımı benzerlik göstermektedir $(p=0,757)$. Birinci grupta kadın hastaların sayısı 11 kontrol grubunda sağlıklı kadın bireylerin sayısı 10 'dur. KBY hastaları ortalama $72,28 \pm 58,93$ aydır diyalize girmektedirler.

$\mathrm{OA}$ ortalama Vmax değerleri KBY'li hasta grubunda sol gözde $56,23 \pm 19,22 \mathrm{~cm} / \mathrm{sn}$, sağ gözde $61,80 \pm 18,24$ $\mathrm{cm} / \mathrm{sn}$ olarak ölçülmüşken, kontrol grubunda sol gözde $40,04 \pm 7,90 \mathrm{~cm} / \mathrm{sn}$ sağ gözde $40,61 \pm 8,55 \mathrm{~cm} / \mathrm{sn}$ olarak ölçülmüştür. İstatistiksel olarak belirgin farklılık saptanmıştır $(P<0,001)$. OA ortalama Vmin değerleri KBY'li hasta grubunda sol gözde $10,76 \pm 3,91 \mathrm{~cm} / \mathrm{sn}$,

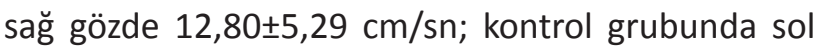
gözde $14,28 \pm 5,14 \mathrm{~cm} / \mathrm{sn}$ sağ gözde $15,23 \pm 5,03 \mathrm{~cm} / \mathrm{sn}$ olarak ölçülmüştür. Sol gözlerde Vmin değerleri arasında istatistiksel olarak anlamlı farklılık saptanmıştır $(P<0,001)$. OA'lerdeki RI değerleri arasında da istatistiksel olarak belirgin farklılık saptanmış olup, diyaliz hastalarında ortalama RI değeri sağ gözde $0,77 \pm 0,05$ sol gözde $0,77 \pm 0,03$ olarak hesaplanmışken kontrol grubunda bu değerler sağ gözde $0,65 \pm 0,03$ sol gözde $0,66 \pm 0,02$ olarak hesaplanmıştır $(P<0,001)$. SRA ortalama Vmax değerleri KBY li hasta grubunda sol

Tablo 1. Hastaların demografik verileri.

\begin{tabular}{|c|c|c|c|c|}
\hline & & Diyalize Giren Hasta Grubu & Kontrol Grubu & P Değerleri \\
\hline \multicolumn{2}{|l|}{ Yaş } & $63,57 \pm 13,79$ yıl & $62,28 \pm 9,24$ yıl & 0,725 \\
\hline \multicolumn{2}{|l|}{ Cinsiyet } & 11 Bayan 10 Erkek & 10 Bayan 11 erkek & \\
\hline Sağ & Vmax & $61,80 \pm 18,24 \mathrm{~cm} / \mathrm{sn}$ & $40,61 \pm 8,55 \mathrm{~cm} / \mathrm{sn}$ & $<0,001$ \\
\hline \multirow{2}{*}{ Oftalmik Arter } & Vmin & $12,80 \pm 5,29 \mathrm{~cm} / \mathrm{sn}$ & $15,23 \pm 5,03 \mathrm{~cm} / \mathrm{sn}$ & 0,101 \\
\hline & RI & $0,77 \pm 0,05$ & $0,65 \pm 0,03$ & $<0,001$ \\
\hline Sol & Vmax & $56,23 \pm 19,22 \mathrm{~cm} / \mathrm{sn}$ & $40,04 \pm 7,90 \mathrm{~cm} / \mathrm{sn}$ & $<0,001$ \\
\hline \multirow[t]{2}{*}{ Oftalmik Arter } & Vmin & $10,76 \pm 3,91 \mathrm{~cm} / \mathrm{sn}$ & $14,28 \pm 5,14 \mathrm{~cm} / \mathrm{sn}$ & $<0,001$ \\
\hline & RI & $0,77 \pm 0,03$ & $0,66 \pm 0,02$ & $<0,001$ \\
\hline Sağ & Vmax & $28,40 \pm 22,47 \mathrm{~cm} / \mathrm{sn}$ & $22,19 \pm 6,20 \mathrm{~cm} / \mathrm{sn}$ & 0,207 \\
\hline \multirow[t]{2}{*}{ Santral Retinal Arter } & Vmin & $8,16 \pm 1,86$ & $8,02 \pm 2,22$ & 0,829 \\
\hline & $\mathrm{RI}$ & $0,67 \pm 0,07$ & $0,66 \pm 0,03$ & 0,447 \\
\hline Sol & Vmax & $22,92 \pm 5,19 \mathrm{~cm} / \mathrm{sn}$ & $19,85 \pm 3,39 \mathrm{~cm} / \mathrm{sn}$ & 0,029 \\
\hline \multirow{2}{*}{ Santral Retinal Arter } & Vmin & $7,82 \pm 1,80 \mathrm{~cm} / \mathrm{sn}$ & $8,09 \pm 1,81 \mathrm{~cm} / \mathrm{sn}$ & 0,630 \\
\hline & $\mathrm{RI}$ & $0,66 \pm 0,05$ & $0,65 \pm 0,02$ & 0,549 \\
\hline \multicolumn{2}{|l|}{ Koroid Kalınlığı } & $165,36 \pm 51,29 \mu \mathrm{m}$ & $291,79 \pm 51,65 \mu \mathrm{m}$ & $<0,001$ \\
\hline
\end{tabular}

Vmax: Maksimum sistolik hız, Vmin: Diyastol sonu hız, Rl: Rezistivite indeks 
gözde 22,92 $\pm 5,19 \mathrm{~cm} / \mathrm{sn}$, sağ gözde $28,40 \pm 22,47$ $\mathrm{cm} / \mathrm{sn}$ olarak ölçülmüşken kontrol grubunda sol göz-

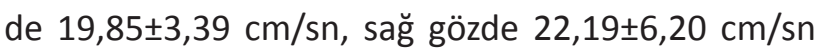
olarak ölçülmüş olup, anlamlı fark saptanmamıştır. SRA'nın Vmin değerleri ve RI değerleri her iki göz için kontrol grubuyla kıyaslandığında anlamlı farklılık saptanmamıştır.

Koroid kalınlıkları karşılaştırıldığında istatistiksel olarak anlamlı fark çıkmış olup, KBY hastalarında koroid kalınlığı ortalaması $165,36 \pm 51,29 \mu \mathrm{m}$ kontrol grubunda ise bu değer $291,79 \pm 51,65 \mu \mathrm{m}$ olarak hesaplanmıştır ( $\mathrm{P}<0,001)$ (Tablo 1).

\section{TARTIŞMA}

Diyabet, hipertansiyon gibi kronik böbrek yetmezliğine neden olan sistemik hastalıkların komplikasyonu olarak göz patolojileri ortaya çıkabildiği gibi KBY'nin kendisinin de neden olduğu hematolojik ve metabolik rahatsızlıklar gözü etkileyebilir. Bu sorunlar erken dönemde tanı konulmadığı takdirde hastanın yaşam kalitesini etkilemekte ve geri dönüşümü olmayan hasarlara yol açabilmektedir ${ }^{8,9}$. Çalışmamızda, diyabet ve hipertansiyona bağıı göz bulgularını ekarte etmek için sistemik rahatsızlıkları bulunan hastalar çalışmaya dahil edilmemiştir.

Göz vasküler patolojilerin açık ve net olarak görüldüğü bir organ özelliğindedir. Bu nedenle KBY tedavisi gören hastalardaki göz bulguları, böbrek yetmezliğinin varlığını ve derecesini yansıtmakta, retina ve retina damarlarında bu değişiklikler farklı derecelerde izlenmektedir ${ }^{9}$.

KBY bulunan hastalarda konjonktiva ve korneada kalsiyum birikimi oldukça sık görülen bir durumdur. Geçmiş dönemlerde retina dekolmanı KBY olan hastalarda oldukça sık bildirilmiş bir durum iken, diyaliz tedavilerinin gelişmesi ve yaygınlaşması sonrasında görülme sıklığı azalmıştır. KBY olan hastalarda makülada irregüler pigmentasyon, fokal koryoretinal atrofik alanların varlığı daha önceden rapor edilmiştir. Yine KBY olan hastalarda iskemiye bağlı optik sinir patolojileri görülebilmektedir. Anlaşıldığı üzere KBY hastalarında göz önemli derecede etkilenmektedir. Göz komplikasyonları geçmişte daha ciddi ve sık görülmesine karşın diyaliz tedavisindeki ilerlemeler ve yaygınlaşma, diyaliz programlarının değişmesi, medikal destek tedavisindeki yenilikler ve sistemik hastalıkların kontrolü sayesinde günümüzde önemli ölçüde azalmıștır ${ }^{10}$.

Diyaliz KBY hastalarının yaşam kalitesini olumlu anlamda etkileyen çok önemli bir tedavi modalitesidir. Hemodiyaliz diğer yöntemlere oranla en sık kullanılan diyaliz yöntemidir ${ }^{11}$.

Çalışmamızda, düzenli diyalize giren KBY olan hastaların retrobulber kan akımları ile birlikte koroid kalınlıklarını değerlendirildi ve normal sağlıklı bireylerle karşılaştırıldı. Tosun ve ark. ${ }^{12}$ çalışmalarında, tek seans diyaliz sonrası retrobulber kan akımındaki değişikleri değerlendirmiştir. Çalışmaları sonucunda, retrobulber kan akım hızında azalma belirlemişlerdir. Yakut ve ark. ${ }^{13}$ çalışmalarında, diyaliz tipinin orbital kan akışı üzerine etkisini değerlendirdi ve periton diyalizine giren hastalarda hemodiyalize giren hastalara nazaran orbital kan akışının daha yüksek olduğunu ve RI değerlerinin daha düşük olduğunu belirtmişlerdir. Saygılı ve ark. ${ }^{14}$ çalışmalarında, son dönem böbrekli yetmezlikli hastalar ile normal sağlıklı bireylerin orbital kan akışını karşılaştırmışlar ve hasta grubunda kan akış hızının yüksek olduğu ve RI değerlerinin düşük olduğunu belirtmişlerdir. Çalışmamız sonucunda, akım hızları yönünden benzerlik göstermekte, ancak RI değerleri diyaliz hastalarında çalışmamızda yüksek olarak hesaplanmıştır. Ayrıca çalışmamızda, orbital kan akımının doppler ile incelemesine ek olarak koroid kalınlıkları da değerlendirilmiştir.

Pahor ve ark. ${ }^{15}$ diyaliz hastalarında OKT bulgularını değerlendirmişler, çalışmalarında 12 diyaliz hastası ile 16 tane sağlıklı bireyi karşılaştırmışlar ve sonuç olarak diyaliz hastalarında koroid kalınlığının belirgin derecede azaldığını belirtmişlerdir. Ulas ve ark. ${ }^{16}$ diyabeti olmayan diyaliz hastalarında diyaliz öncesi ve sonrasında koroid ve retina kalınlıklarını değerlendirmişler, retina kalınlığında anlamlı fark olmadığını ancak koroidde belirgin incelme olduğunu belirtmişlerdir. 
Ishibazawa ve ark.'da ${ }^{17}$ diyabeti olan ve olmayan hasta gruplarında diyaliz öncesi ve diyaliz sonrası koroid kalınlıklarını karşılaştırmış ve her iki grupta da koroid kalınlığında diyaliz sonrasında azalma saptamışlardır. Yang ve ark.'da ${ }^{18}$ çalışmalarında, diyaliz sonrasında koroid kalınlığındaki azalmayı belirtmişlerdir. Çalışmamız sonucunda da, diyaliz hastalarında normal sağlıklı bireylerle karşılaştırıldığında, koroid kalınlıklarında azalma belirlenmiştir. Çalışmamızda, yukaridaki çalışmalardan farklı olarak oküler kan akımı da değerlendirilmiştir. Çalışmamız, bildiğimiz kadarıyla oküler kan akımı ile birlikte koroid kalınlığının diyaliz hastalarında ve normal popülasyonun karşılaştırılarak değerlendirildiği ilk çalışmadır. Mevcut olan çalışmalar yukarıda da söz edildiği gibi genellikle diyaliz öncesi ve sonrası koroid kalınlıklarının karşılaştırılması ya da oküler kan akımı bakılmaksızın normal sağııkı bireylerle diyaliz hastalarında koroid kalınlığının karşılaştırılması şeklindedir.

Çalışmamızın sonucu olarak, düzenli diyalize giren KBY hastalarında özellikle oftalmik arterde belirgin olmak üzere orbital kan akış hızı belirgin olarak arttığını, RI değerlerininde bu hastalarda vasküler direncin arttığını düşünmemize neden olacak şekilde yüksek olarak ölçülmüştür. Aynı zamanda normal popülasyonla kıyaslandığında KBY hastalarında koroid kalınlığının da azaldığı izlenmiştir. Hipertansif ya da diyabetik retinopatisi olmayan KBY hastalarında kolaylıkla ve düzenli şekilde belli aralıklarla yapılan doppler inceleme tetkiki ile orbital kan akışının değerlendirilmesi bu hasta grubunda erken dönemde olacak değişikliklerle erken tanı ve tedavi açısından avantaj sağlayacaktır.

\section{KAYNAKLAR}

1. Easterbrook $M$, Mortımer $\mathrm{CB}$. Oculer signs in chronic renal failure. Br J Ophthalmol 1970;54:724-730. https://doi.org/10.1136/bjo.54.11.724

2. Spaide RF, Koizumi H, Pozonni MC. Enhanced depth imaging spectral-domain optical coherence tomography. Am J Ophthalmol 2008;146:496-500. https://doi.org/10.1016/j.ajo.2008.05.032

3. Margolis R, Spaide RF. A pilot study of enhanced depth imaging optical coherence tomography of the choroid in normal eyes. Am J Ophthalmol 2009;147:811-815. https://doi.org/10.1016/j.ajo.2008.12.008

4. Hua R, Liu L, Lib C, and et al. Evaluation of the effects of photodynamic therapy on chronic central serous chorioretinopathy based on the mean choroidal thickness and the lumen area of abnormal choroidal vessels. Photodiagnosis Photodyn Ther 2014;11:519-525. https://doi.org/10.1016/j.pdpdt.2014.07.005

5. Behdad B, Rahmani S, Montahaei T, and et al. Enhanced depth imaging OCT (EDI-OCT) findings in acute phase of sympathetic ophthalmia. Int Ophthalmol 2015;35:433-439. https://doi.org/10.1007/s10792-015-0058-6

6. Liew WE. Color doppler ultrasonography of the eye and orbit. Curr opin Ophtalmol 1993;4:68-75. https://doi.org/10.1097/00055735-199306000-00012

7. Mulhern M, Hulsmans F, Geussen HC. Resistivity indicis in CDI of ocular vessels. Ophtalmology 1996;103:1333-4. https://doi.org/10.1016/S0161-6420(96)30500-9

8. Soylu M, Güleç A, Noyan A. Hemodiyaliz tedavisi uygulanan çocuklarda oküler bulgular. MN Ophthalmol 1998;5(1):17-20.

9. Oto $S$, Aydın P. Kronik böbrek yetmezliği ve göz ön-1 segment bulguları. T Oft Gaz 1995;25:132-135.

10. Demir MN, Kocaoglan H, Akay $H$, ve ark. Kronik böbrek yetmezliğinde göz bulguları. T Oft Gaz 2006;36:150-155.

11. Sivrikaya A, Aköz M, Altıntepe L. Kronik böbrek yetmezliğ olan hemodiyaliz hastalarında ve sağlıklı kontrollerde serum $\mathrm{Zn}, \mathrm{Cu}, \mathrm{Fe}, \mathrm{Cd}, \mathrm{TT} 3, \mathrm{TT} 4, \mathrm{PTH}$ VE TIBC seviyeleri. Van Tıp Dergisi 2010;17:36-41.

12. Tosun Ö, Davutluoglu B, Arda K, ve ark. Determination of the effect of a single hemodialysis session on retrobulbar blood hemodynamics by color doppler ultrasonography. Acta Radiologica 2007;7:764-767. https://doi.org/10.1080/02841850701348713

13. Yakut Z, Karadag R, Akcay A, and et al. Effect of dialysis type on orbital vascular flow in patients with end-stage renal disease. Renal Failure 2012;34:691-696. https://doi.org/10.3109/0886022X.2012.681532

14. Saygili O, Pelit A, Torun D, and et al. Value of color doppler ultrasonography in the evaluation of orbital vascular flow in end-stage renal disease patients undergoing hemodialysis. Acta Radiologica 2004;45:854-858. https://doi.org/10.1080/02841850410008414

15. Pahor D, Gracner B, Gracner T, and et al. Optical coherence tomography findings in haemodialysis patients. Klin Monbl Augenheilkd 2008;8:713-7. https://doi.org/10.1055/s-2007-963761

16. Ulas F, Dogan U, Keles A, and et al. Evaluation of choroidal and retinal thickness measurements using optical coherence tomography in non-diabetic haemo-dialysispatients. Int Ophthalmol 2013;2:533-9. https://doi.org/10.1007/s10792-013-9740-8

17. Ishibazawa A, Nagaoka T, Minami Y, and et al. Choroidal thickness evaluation before and after hemodialysis in patients with and without diabetes. Invest Ophthalmol Vis Sci 2015;11:6534-41. https://doi.org/10.1167/iovs.15-16719

18. Yang SJ, Han YH, Song GI, and et al. Changes of choroidal thickness, intraocular pressure and other optical coherence tomographic parameters after haemodialysis. Clin Exp Optom 2013;5:494-9. https://doi.org/10.1111/cxo.12056 